\title{
O período áureo da dermatologia em Viena (O legado dos nossos ancestrais numa excepcional conjunção de astros) *
}

\author{
Prof. Dr. Ney Romiti
}

O procurar entender dentro do ciclo evolutivo de uma especialidade médica o motivo do renome alcançado por uma clínica que se diferencia e passa a ser reconhecida internacionalmente, desperta sempre a curiosidade científica. É fato inconteste que merece distinção a supremacia de liderança com a repercussão alcançada pela dermatologia de Viena, que por décadas impera na medicina dermatológica.

Assim, necessário se faz e imprescindível se torna que aqueles que objetivem entender em detalhe esse período brilhante consultem as publicações de $\mathrm{K}$. Holubar e J. Frankl. ${ }^{1}$ Nesta, detalhes da vida do eminente Moriz Kaposi é relatada em marcantes pormenores, quando esclarece, entre outros fatos o preponderante motivo da mudança do nome de Moriz Kohn para Moriz Kaposi, assim também o seu registro de nascimento na comunidade judaica em Kaposvár na Hungria. Também a íntima ligação profissional e familiar com a família de F. Hebra que se torna ainda mais estreita pelo casamento com Martha, a filha de Hebra

.A escola de Viena (L'école de Vienna) é fundada pelo imperador Rudolf IV em 1365 e a Universidade de Viena inicia suas atividades a partir do século XVIII impulsionada por Gérard van Swieter (Leyde) quando aceita o convite feito pela imperatriz Marie Thérèze, para construir uma política de saúde. É na cátedra que se inicia a nova escola dermatológica na qual sobressai F. Hebra, com carreira de realce no Serviço de Carl von Rokitansky, figura exponencial na medicina contemporânea. Logo, em sequência passa a freqüentar o serviço de pneumologia de Skoda. É neste ambiente que Hebra contacta os primeiros pacientes com doenças na pele, quando num departamento isolado praticamente abandonado inclusive evitado pelos médicos do hospital (departament des galeux). É neste contexto que por influência de Skoda a orientação para que o jovem Hebra se inicie a consultar os diversos tratados de dermatologia da época, na verdade elementares e qualidade científica duvidosa. É assim que partindo de uma situação rudimentar, fornece ao governo austríaco subsídios para que a disciplina dermatologia passasse a ter ensinamento específico e carga docente correspondente. ${ }^{4}$
Hebra foi leitor atento de d'Alibert, mas o seu enorme sucesso como Mestre pode ser julgado pelo legado testemunhal de um de seus alunos, o americano George Henry Fox... "De todos os professores da clínica de Viena o prof. Hebra, foi sem dúvida o mais popular não só por sua reputação científica, por seus métodos de ensino e o seu admirável humor. Um estudante alemão na época fez comentário notável afirmava " que nada tinha a fazer na dermatologia mas que os ensinamentos de Hebra valiam mais do que todas as apresentações nos teatros de Viena”.

Dois grandes viajantes da dermatologia L.A. Duhring e A. Doyon nos oferecem nas suas lembranças, testemunho precioso da atmosfera que imperava na Allgemeines Krankenhaus de Viena onde se pode em toda intensidade sentir o cotidiano não só dos professores docentes, mas também o modo de atendimento sócio-hospitalar..."O departamento das doenças de pele, segundo Duhring se compõe em seu conjunto de oito salas, sendo a direção desse departamento feita por F. Hebra..., mister Hebra, examina pessoalmente todos os doentes, dedicando duas horas diárias a esta função, nesta sendo auxiliado por seu assistente Dr. Moriz Kohn-Kaposi. Às 7 horas da manhã o professor Hebra inicia o seu ensinamento clínico em um anfiteatro vizinho às enfermarias. ${ }^{4}$

Nascido em Kaposvár, Moriz Kaposi, em 1837 é docente em medicina em 1861 e após estagiar por dois anos na clínica de sífilis de Sigmund se torna assistente de Hebra. Mais uma vez, é pela herança de correspondência que se amplia o conhecimento no ambiente hospitalar na clínica de Viena, pelo testemunho herdado de William Dubreuilh após visita... "Kaposi ao entrar na cátedra e tomar seu lugar inicia sua aula em francês. Após suas primeiras frases, eu o interrompo e informo que compreendia bem o alemão, mas ele mantém o mesmo idioma... coqueteria de um poliglota". Ele está sem dúvida algo influenciado pela tradição de F, Hebra, seu predecessor e sogro (...). Seus assistentes, Riehl, Nobl mesmo quando não compartilham da opinião de seu chefe, não ousam discordar...

Comentava-se na intimidade que Kaposi casarase com Martha, a filha de Hebra, herdara sua casa, sua 
cátedra e a clientela, deixando o resto para o cunhado Hans Hebra...

Sem dúvida a escola dermatológica de Viena durante o período Hebra-Kaposi domina a dermatologia do século XVIV, não só por sua rica contribuição ao conhecimento das doenças de pele, mas também por sua enorme capacidade de organização que seria necessária para o desenvolvimento da dermatologia.

Digno ainda de registro em íntima relação com o áureo período do desenvolvimento da dermatologia em Viena, necessário se faz realçar e incluir como personagem de grande importância e nesse momento um professor que é parcialmente esquecido quando preponderam Hebra e Kaposi. Assim justiça se faça ao papel desempenhado por Sigmund especialista em sífilis, como epidemiologista e higienista. Mérito tem K. Holubar quando valorizando Sigmund compara a igualdade curricular que se desenvolvia paralela ao de Hebra. ${ }^{4}$ Holubar fornece esses parâmetros ao nos relatar o elogio de Fingr feito por ocasião de jornada médica em Viena em 1913... "Dentre os heróis que pontificaram no áureo período da escola de medicina em Viena, sem dúvida, Sigmund foi aquele com a melhor formação acadêmica e ampla visão no que em muito superava Hebra“. Foi homem com rara energia intelectual, física e perseverança. ${ }^{4}$

\section{REFERÊNCIAS}

1. Karl Holubar-József Frankl (Dermatologie in historical perspectif) "American Journal of Dermatopathologie. vol 3, number 4, winter 1971 (p 349-54)".

2. La naissance de la dermatologie (1776- 1880). Gérard Tilles, Capítulo VIII, p. 75-84.

3. Doctor Weidenfeld-Moriz Kaposi (In memorian). The American Journal of Dermatopathologie, vol 3 number 4, winter 1971 p. 355-8.

4. Karl Holubar-Entwicklungen der Dermatologie in Oesterreich (15 pag-201-215, 1989) Dermatologie (Burg) ed. Urban e Schwarzenberg (ISBN. 3-541-11621-8). 